\title{
Expression of cytochrome P450 CYP6B6 in the different developmental stages of the insect Helicoverpa armigera (Lepidoptera: Noctuidae)
}

\author{
Xuetao ZHANG, Dan YUAN, Li DING, Pan LI, Fen LI and Xiaoning LiU* \\ College of Life Science and Technology, Xinjiang University, Xinjiang Key Laboratory of Biological Resources and Genetic \\ Engineering, Urumqi 830046, China; e-mails: zhxt51@163.com; 79546571haha@sina.com; 2012dingli@sina.com; \\ lipan19860706@yahoo.com.cn; lifen2010happy@sina.com; liuxn0103@sina.com
}

Key words. Lepidoptera, Noctuidae, Helicoverpa armigera, developmental stage, CYP6B6 expression

\begin{abstract}
In order to determine when during the development of H. armigera CYP6B6 is expressed, we measured the width of the head capsule, the length of the body and weight of the different life stages of the cotton bollworm reared under laboratory condition. The larvae took about $20 \mathrm{~d}$ to complete their development under these conditions, the pre-pupae about $4 \mathrm{~d}$, pupae about $9 \mathrm{~d}$, and the adults lived for about $9 \mathrm{~d}$ and the eggs took about $4 \mathrm{~d}$ to hatch. Knowing this it was possible to determine the pattern of cytochrome P450 CYP6B6 expression at different stages in the life cycle of $H$. armigera using real-time quantitative polymerase chain reaction (RT-qPCR). The CYP6B6 gene was expressed in all the developmental stages of the cotton bollworm. The results indicate that the level of expression was lower in the egg, pre-pupal, pupal and adult stages than in larvae. The level of expression of CYP6B6 decreased from the $1^{\text {st }}$ to the $3^{\text {rd }}$ instar larva, with the lowest level recorded in the $3^{\text {rd }}$ instar larvae and then increased reaching its highest value in $6^{\text {th }}$ instar larvae. A similar trend in the expression of CYP6B6 was detected using immunohistochemistry. As the results show, more efficient control of the cotton bollworm can be achieved if insecticides are applied when the larvae of $H$. armiger are in the $3^{\text {rd }}$ instar, because at that stage the eat little food and there is a low level of detoxifying enzymes in the larvae.
\end{abstract}

\section{INTRODUCTION}

Helicoverpa armigera (Lepidoptera: Noctuidae) is a major insect pest of a wide range of agricultural and commercial crops in many parts of the world, including China. The persistence of this pest in modern agriculture is mainly attributed to its resistance to commonly applied insecticides and ability to feed on a wide array of host plants (Tan et al., 1996; Forrester et al., 1993; Qiu et al., 2003). In insects, enzymatic detoxification of plant toxins and insecticides is a well documented, common and important mechanism of host plant adaptability and insecticide resistance (Forrester et al., 1993; Wu et al., 1997; Li et al., 2002; Yang et al., 2004; Chen et al., 2005). Among the insect detoxification systems, cytochrome P450 monooxygenases are the most prominent. The cytochrome P450s play many roles in insects, including synthesis of hormones and pheromones, fatty acid metabolism, and degradation of host plant toxins and insecticides (Feyereisen, 2005). An increase in insecticide detoxification by $\mathrm{P} 450$ s and other enzymes is a common mechanism of insecticide resistance.

Inducibility is a general characteristic of cytochrome P450 (Harrison et al., 2001). Induction of cytochrome P450 genes by chemicals such as allelochemicals and some insecticides, is well documented (Feyereisen, 2005). There is a link between exogenous compounds acting as inducers and the induced enzymes metabolizing them in insect detoxification systems (Willoughby et al., 2006). Previous studies focused on the tissue distribution, developmental expression of P450 monoxygenases as a whole, their interactions with xenobiotic compounds and insecticide resistance (Qiu et al., 2000, 2001; Li et al., 2002). For example, the p-nitroanisole O-demethylase activity of P450s and the expression of CYP6B6 mRNA induced by two plant secondary substances, 2-tridecanone and quercetin, have been investigated in the cotton bollworm, $H$. armigera. The O-demethylase activity is higher in the fat body than in the midgut of $6^{\text {th }}$ instar larvae fed on artificial diets mixed with these allelochemicals. Similar results were obtained when induced by a combination of 2-tridecanone and quercetin at different concentrations (Liu et al., 2006). In $H$. armigera there are several mechanisms of resistance to pyrethroids (Ahmad et al., 1989; Gunning et al., 1991; McCaffery et al., 1997), but the characterization of individual cytochrome P450 in this insect is difficult due to the genetic diversity, broad substrate specificity and catalytic versatility of cytochrome P450s. However, molecular and immunology approaches have enabled investigators to study the expression profile of individual P450s in insects.

In the present study we determined the level of expression of CYP6B6 and the distribution of CYP6B6 protein in the tissues of the different developmental stages of the cotton bollworm. This was done after determining the duration of each of its life stages. This study also provides evidence that it is best to apply pesticides to control the cotton bollworm when it is in the $3^{\text {rd }}$ instar, because little food is ingested during this instar and the level of expression of detoxifying enzymes is low.

\footnotetext{
* Corresponding author.
} 


\section{MATERIAL AND METHODS}

Insect

The laboratory strain of $H$. armigera came from China Agricultural University and was reared on an artificial diet at $28 \pm$ $1{ }^{\circ} \mathrm{C}, 70-80 \%$ relative humidity, under a photoperiod of $16 \mathrm{~L}$ : $8 \mathrm{D}$. Adults were kept under the same temperature and light conditions, and provided with a $10 \%$ honey solution. Composition of the artificial diet was: corn flour $300 \mathrm{~g}$, soybeans powder 100 g, yeast extract powder $100 \mathrm{~g}$, citric acid $2.5 \mathrm{~g}$, vitamin C $10 \mathrm{~g}$, sorbic acid $1.5 \mathrm{~g}$, vitamin B $1.5 \mathrm{~g}$, erythromycin $0.05 \mathrm{~g}$, propionic acid $5 \mathrm{~mL}$, vitamin $\mathrm{E}$, water $2.5 \mathrm{~L}$.

\section{Reagents}

The primary antibody was prepared by our research team, secondary antibody (goat anti-rabbit), diaminobenzidine (DAB) chromogenic kit were purchased from Zhangshan goldbridge in China, TRIzol reagent, real master mix SYBR green PCR kit from invitrogen in USA, DNase I, oligo(dT)18primer (50 mM), RNase M-MLV(RNase H-), RNase inhibitor, dNTP mixture (2.5 $\mathrm{mM}$ ) from Takara Bio. Inc. in China, and all other reagents were of analytical quality and from Tianjin Fuyu Fine Chemical Co., Ltd.

\section{Pattern of developmental of $\boldsymbol{H}$. armigera}

Daily measurements and observations were made on all stages from egg to adult, and the adults that emerged were transferred to a cage. During the larval period, the width of the head capsule of each larva $(n=180)$ was measured daily using a stereoscopic microscope (Nikon Instruments Inc. USA) and its body weight determined using an electronic balance (Mettler Toledo Inc. China). At the same time, the length of each larva was measured. The relationship between larval instars and developmental duration was analyzed using linear regression.

\section{The relative expression of $C Y P 6 B 6$ at different stages in the development}

RNA isolation and cDNA synthesis

Total RNA from the different developmental stages of $H$. armigera was extracted using TRIzol according to the manufacture's instructions. The quality and concentration of RNA samples were determined using agarose gel electrophoresis and NanoDrop-1000 (Thermo Scientific Inc. USA). RNA was digested by DNase I in order to eliminate genomic DNA contamination. cDNA was synthesized by reverse transcription in $20 \mu \mathrm{L}$ reaction system according to the manufacture's instructions. Three independent RNA preparations, representing three biological replicates, were used for the cDNA synthesis.

\section{Real-time RT-PCR analysis}

The levels of expression of the CYP6B6 gene in the different developmental stages of $H$. armigera were quantified using a real-time quantitative polymerase chain reaction (RT-qPCR), a 7500 Real Time PCR System (Applied Biosystems, USA) and a real master mix SYBR Green PCR kit. The elongation $\beta$-actin was used as a reference gene to normalize the target gene expression levels recorded in the different samples. RT-PCR of each cDNA sample and template-free was performed in triplicate. All the primers sets used in this study were listed as follows. Specificity of the PCR amplification was checked by a melt curve analysis and by sequencing the PCR products. qTR-PCR was run in a $25 \mu \mathrm{L}$ reaction system, which contained $12.5 \mu \mathrm{L}$ of real master mix SYBR solution, $0.5 \mu \mathrm{L}$ each of forward and reverse primers $(10 \mu \mathrm{M}), 1 \mu \mathrm{L}$ of cDNA template and $10.5 \mu \mathrm{L}$ of $\mathrm{ddH}_{2} \mathrm{O}$ using the following cycling parameters: $95^{\circ} \mathrm{C}$ for $2 \mathrm{~min}$, followed by 40 cycles of $95^{\circ} \mathrm{C}$ for $30 \mathrm{~s}, 62^{\circ} \mathrm{C}$ for $30 \mathrm{~s}$ and $72^{\circ} \mathrm{C}$ for $30 \mathrm{~s}$. The relative expression levels of target genes were calculated using the comparative CT method. Primers of CYP6B6 and $\beta$-actin $\left(5^{\prime} \sim 3^{\prime}\right)$ : CYP6B6: F: TTCAAACTTATACCATGTCCACAATT, R: CCAATTGACGGAGCTCTAGAATCA; $\beta$-actin: F: ATCATCGACGCTCCCGGACA, R: TAGCTGCTTGACTCCGAGGGTG.

Presence and abundance of CYP6B6 protein in cross sections of the mid-gut of the different larval stages of $H$. armigera

The expression levels of CYP6B6 protein in the different larval atages were analyzed using an immunohistochemical method. The expression of CYP6B6 protein was determined in transverse sections of the body of $1^{\text {st }}, 2^{\text {nd }}$ and $3^{\text {rd }}$ instar larvae, and transverse sections of the mid-gut of $4^{\text {th }}, 5^{\text {th }}$ and $6^{\text {th }}$ instar larvae, after fixation, dehydration, embedding, sectioning, dewaxing, incubating with antibody and staining with DAB.

\section{Statistical analysis}

The relationship between larval instars and developmental durations was analyzed using linear regression. The number of instars was established graphically (Taylor, 1931) and confirmed using the confidence intervals of the measurements. The analysis was done using GraphPad Prism 4 software.

\section{RESULTS}

\section{Larval period}

Head capsule width, body length, body weight and duration of developmental of $H$. armigera are given in Table 1. The graphic method revealed six well defined frequency peaks at head capsule widths of $0.25,0.41$,

TABLE 1 . Head capsule width, body length and body weight of $H$. armigera .

\begin{tabular}{ccccc}
\hline $\begin{array}{c}\text { Developmental } \\
\text { phase }\end{array}$ & $\begin{array}{c}\text { Head capsule }(\mathrm{mm}) \\
\text { Mean } \pm \mathrm{SE}\end{array}$ & $\begin{array}{c}\text { Length }(\mathrm{mm}) \\
\text { Mean } \pm \mathrm{SE}\end{array}$ & $\begin{array}{c}\text { Weight }(\mathrm{mg}) \\
\text { Mean } \pm \mathrm{SE}\end{array}$ & $\begin{array}{c}\text { Duration }(\mathrm{d}) \\
\text { Mean } \pm \mathrm{SE}\end{array}$ \\
\hline $1^{\text {st }}$ larvae & $0.25 \pm 0.02$ & $1.56 \pm 0.24$ & $1.1 \pm 0.88$ & $2.89 \pm 0.65$ \\
$2^{\text {nd }}$ larvae & $0.41 \pm 0.02$ & $3.88 \pm 0.59$ & $3.12 \pm 1.76$ & $3.23 \pm 0.98$ \\
$3^{\text {rd }}$ larvae & $0.63 \pm 0.04$ & $5.07 \pm 0.93$ & $8.33 \pm 5.58$ & $3.25 \pm 0.98$ \\
$4^{\text {th }}$ larvae & $1.06 \pm 0.09$ & $11.02 \pm 2.57$ & $13.58 \pm 3.26$ & $3.43 \pm 0.91$ \\
$5^{\text {th }}$ larvae & $1.6 \pm 0.16$ & $19.34 \pm 3.6$ & $19.32 \pm 4.9$ & $3.73 \pm 0.69$ \\
$6^{\text {th }}$ larvae & $2.53 \pm 0.1$ & $27.91 \pm 3.9$ & $28.59 \pm 6.2$ & $3.70 \pm 0.50$ \\
prepupa & & & $24.85 \pm 2.28$ & $3.89 \pm 0.72$ \\
pupa & & & $22.24 \pm 3.34$ & $8.92 \pm 0.32$ \\
adult & & & $9.21 \pm 0.68$ \\
egg & & & $3.80 \pm 0.75$ \\
\hline
\end{tabular}




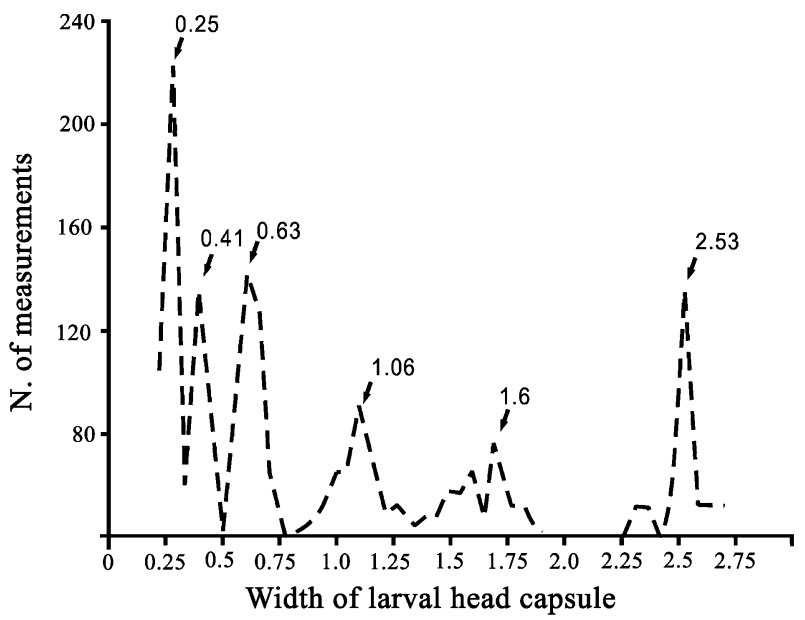

Fig. 1. Frequency distribution of head capsule widths of the different larval stages of $H$. armigera reared at $27 \pm 1{ }^{\circ} \mathrm{C}$ and $70-80 \%$ RH.
$0.63,1.06,1.6$ and $2.5 \mathrm{~mm}$, indicating six larval instars (Fig. 1), in addition, the duration of development of $1^{\text {st }}$ instar larvae was about $2.89 \mathrm{~d}$ and that of the other developmental stages about $3 \mathrm{~d}$ (Table 1). The period of time spent in each instar increased linearly was defined by the following relationship: $\mathrm{Y}=0.16 \mathrm{X}+2.8\left(\mathrm{R}^{2}=0.93\right)$, which indicates that the developmental time of each successive instar was $0.16 \mathrm{~d}$ longer than that of the previous instar. The total duration of development from the $1^{\text {st }}$ to the $6^{\text {th }}$ instar lasted about $20 \mathrm{~d}$. We also observed that the dorsal surface of the larvae of $H$. armigera became more and more translucent and darker in colour and the crack in the middle of the head capsule increased in width in the latter instars (red arrows in Fig. 2). Similarly, the longitudinal line of the dorsum of the larvae became more and more translucent and darker in colour from the $1^{\text {st }}$ instar larva to the prepupal stage (red arrows in Fig. 3) (Wu, 1977).

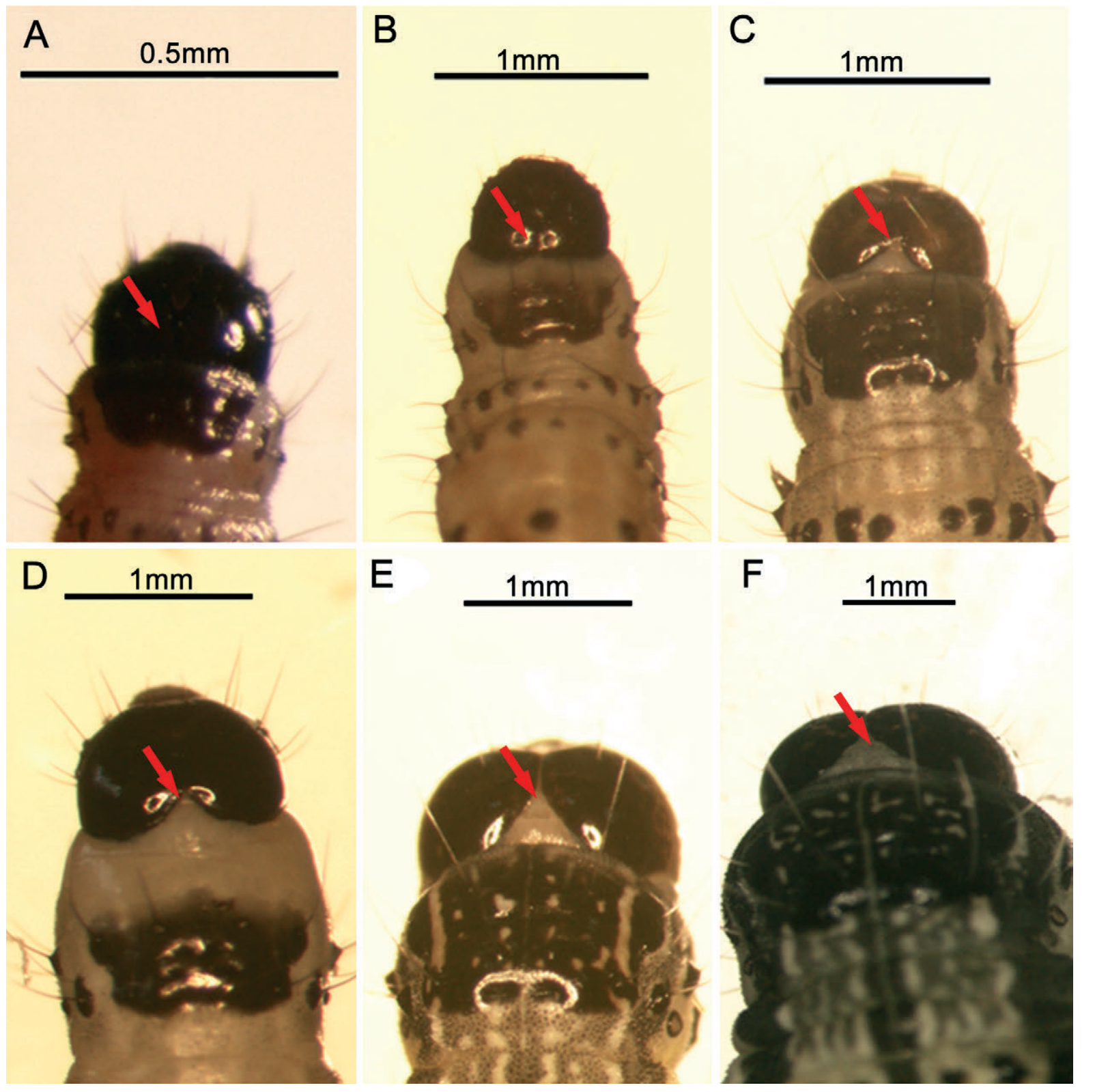

Fig. 2. Pictures illustrating the changes in head capsule width of $H$. armigera at different stages of development. For explanation of the red arrows see the corresponding text. 
A

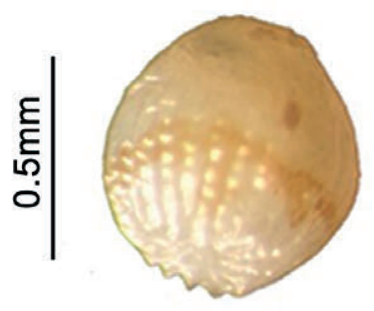

B

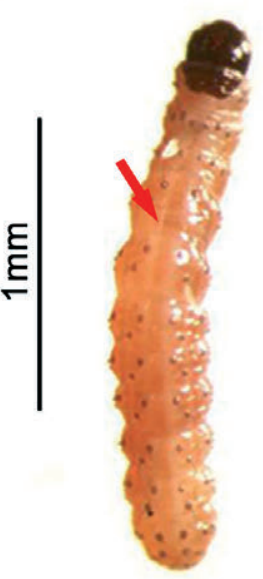

I

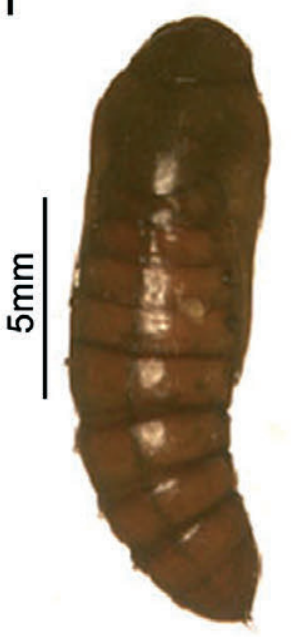

C

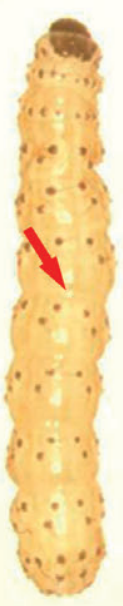

$\mathrm{H}$

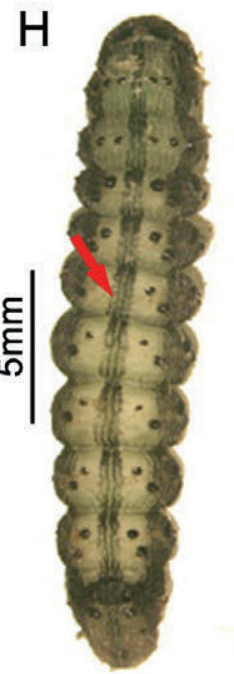

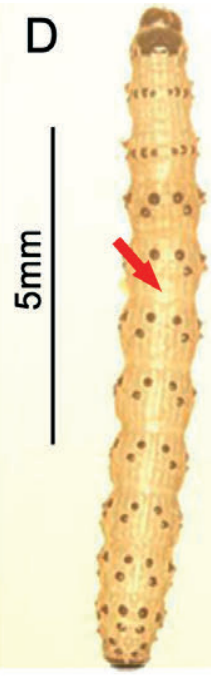

G

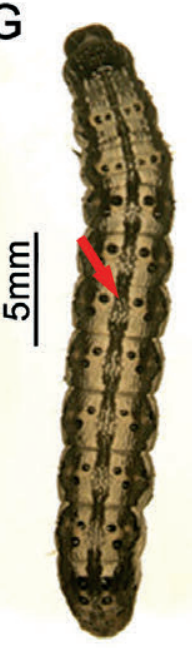

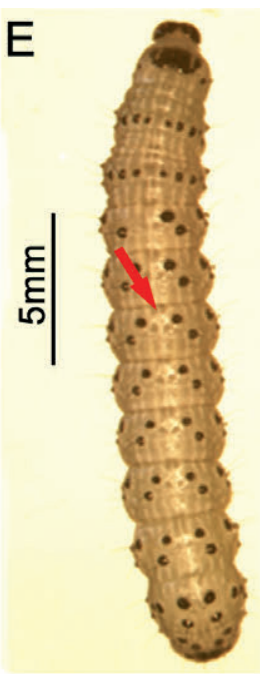

$\mathrm{F}$

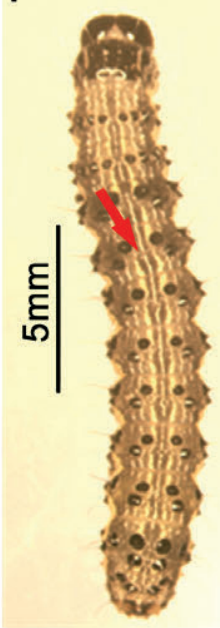

Fig. 3. The morphological features of $H$. armigera at different stages of development. A - egg; $\mathrm{B}-\mathrm{G}-1^{\text {st }}$ to $6^{\text {th }}$ instar active larvae; $\mathrm{H}$ - prepupa; I - pupa; J - adult. For explanation of the red arrows see the corresponding text.

\section{The duration of prepupa, pupa, adult and egg}

The duration of the prepupal period was $3.89 \pm 0.72 \mathrm{~d}$ and the prepupa weighed $24.85 \pm 2.28 \mathrm{mg}$. The duration of the pupal period was $8.92 \pm 0.32 \mathrm{~d}$ and the pupa weighed $22.24 \pm 3.34 \mathrm{mg}$. The adult lived for $9.21 \pm 0.68$ $\mathrm{d}$ and the eggs took $3.80 \pm 0.75 \mathrm{~d}$ to hatch (Table 1 ).

\section{Levels of expression of the CYP6B6 gene in the different developmental stages}

RNA was extracted from the different developmental stages of cotton bollworm using reverse transcription cDNA as a template, $\beta$-actin as a reference gene to calculate the relative level of expression of $C Y P 6 B 6$ gene using $2^{-\Delta \Delta \mathrm{CT}}$. The results show that $C Y P 6 B 6$ was expressed in all the developmental stages of the cotton bollworm. From the $1^{\text {st }}$ instar to the $3^{\text {rd }}$ instar larvae there was a decrease in the level of expression of $C Y P 6 B 6$, reaching the lowest level in the $3^{\text {rd }}$ instar larvae, and then increasing to a maximum in $6^{\text {th }}$ instar larvae. The level of expression of CYP6B6 was greater in the larval stages than in other developmental stages, in which the level was very low (Fig. 4).

\section{Presence and abundance of CYP6B6 protein in cross sections of the mid-gut of larvae}

The immunohistochemical reaction with the CYP6B6 antibody was mainly observed in larvae. CYP6B6 occurred mostly in the mid-gut and fat body (Fig. 5). The staining in the midgut became more intense as the larvae

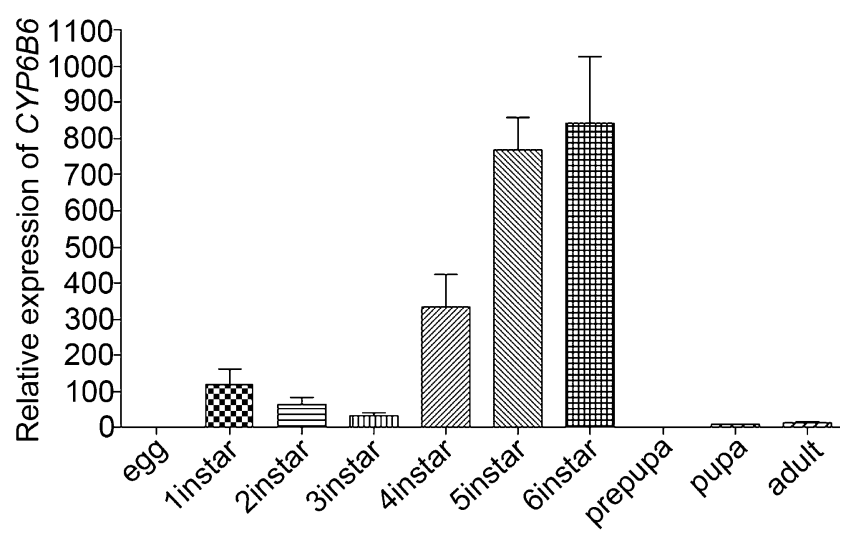

Fig. 4. The relative expression of CYP6B6 in the different developmental stages of $H$. armigera. 


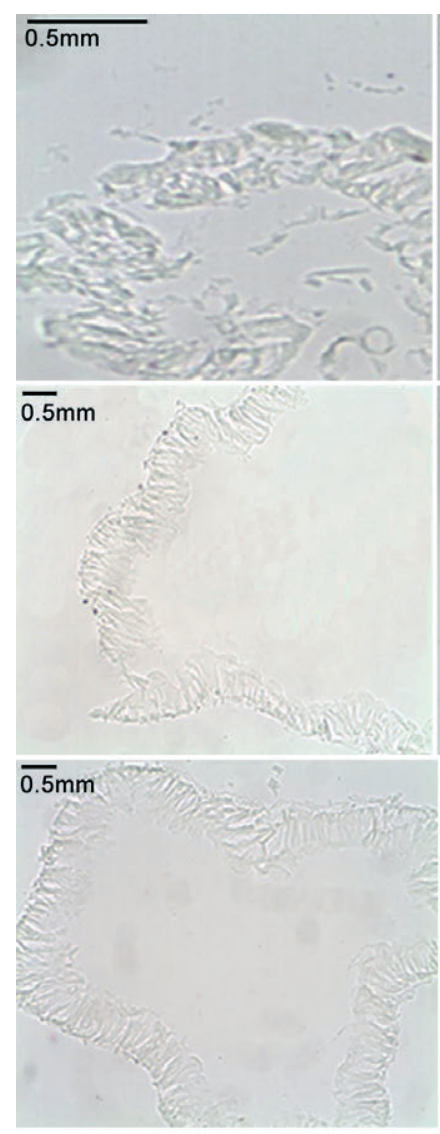

Untreated
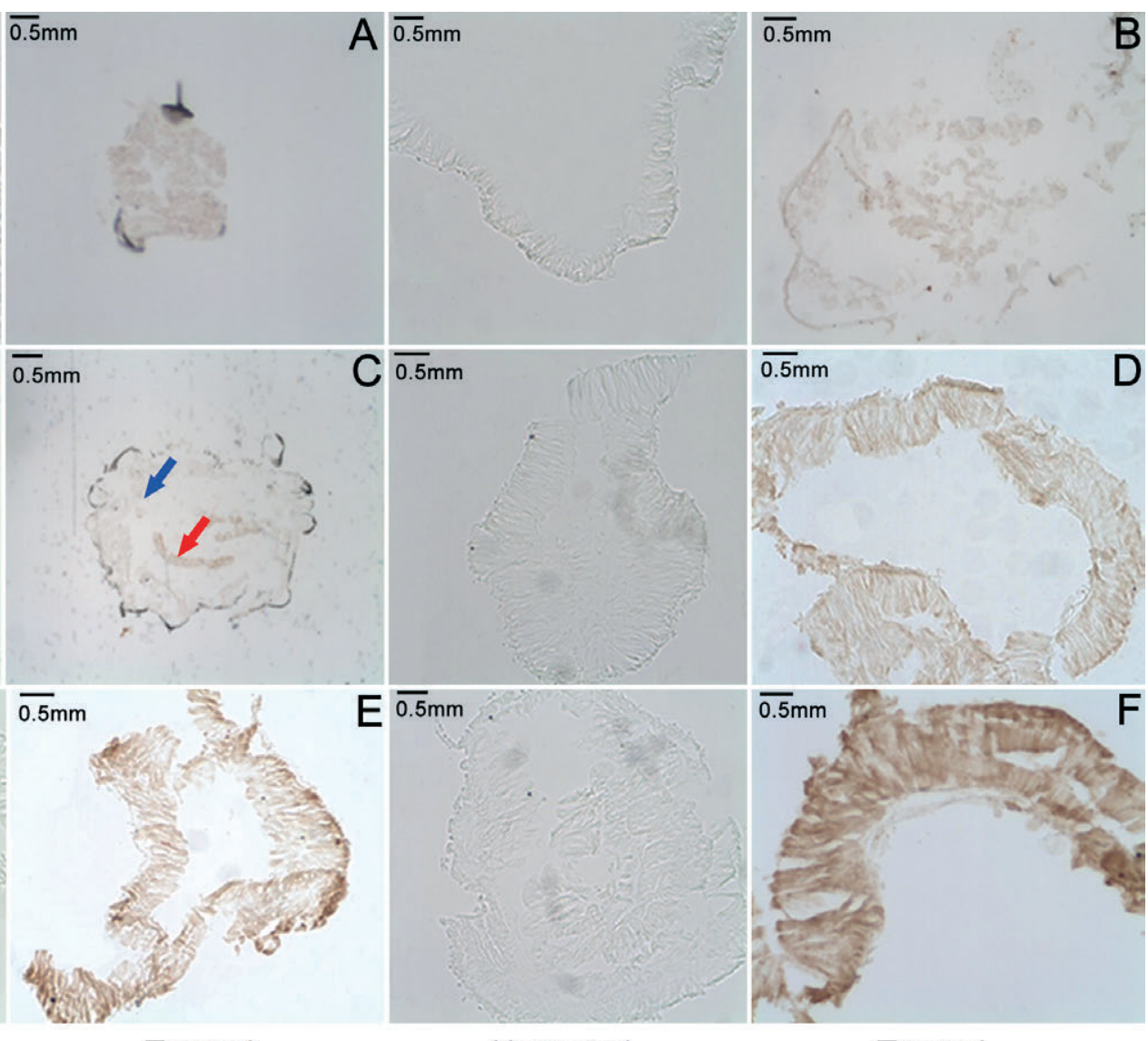

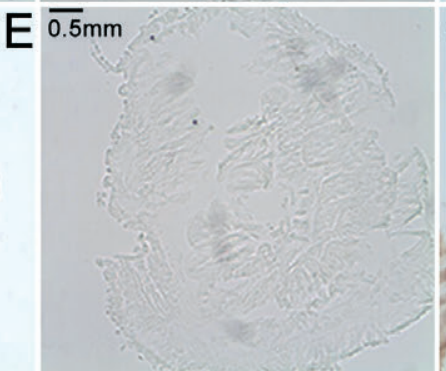

Untreated

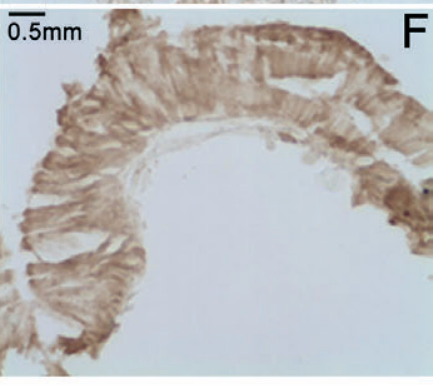

Treated

Fig. 5. Transverse sections of the mid-gut of larvae of H. armigera stained to show the presence and level of expression of cytochrome P450 CYP6B6. A-F - transverse sections through the mid-gut of $1^{\text {st }}-6^{\text {th }}$ instar larvae, respectively. Untreated group - not incubated with antibodies, treated group - incubated with antibodies. Red arrow indicates mid-gut and blue arrow fat body.

developed. From the $1^{\text {st }}$ to $3^{\text {rd }}$ instar larvae there was decrease in the amount of CYP6B6 protein reaching its lowest level in $3^{\text {rd }}$ instar larvae, and then increasing to a maximum in $6^{\text {th }}$ instar larvae, which is similar to the trend in CYP6B6 mRNA expression.

\section{DISCUSSION}

The growth and development of cotton bollworm larvae is affected by a variety of factors, including temperature, humidity, photoperiod and host plant (Jiang et al., 1998; Hunter \& McNeil, 1997; Liu et al., 2004). There is a big difference in the duration of development of larvae reared on an artificial diet or a host plant. The developmental time of immature stages ranged from $26.6 \mathrm{~d}$ to $35.1 \mathrm{~d}$ on six different host plants, cotton, tomato, hot pepper, tobacco and common bean (Liu et al., 2004). H. armigera larvae reared on different artificial foods take longer to complete their development. The lower amount of protein in artificial diets affects the growth and development of larvae and fecundity of adults (Wu \& Li, 1993). In this study the larvae reared under laboratory conditions on an artificial diet took about $20 \mathrm{~d}$ to complete their development. The individual larval body lengths and weights recorded in each instar varied greatly whereas the head capsule widths did not (Table 1). Thus, the instar of indi- vidual larvae is more accurately identified using head capsule width than any of the other measurements.

Enzymatic and metabolic studies have long shown that insect cytochrome P450s play a major role in the detoxification of synthetic insecticides (Brattsten et al., 1986; Hodgson et al., 1995). The expression of cytochrome $\mathrm{P} 450 \mathrm{~s}$ is quite different in the different developmental stages or at different periods in the same developmental stage, and the enzyme activity and content are also different in the different developmental stages of $H$. armigera. Higher monooxygenase activity/content is usually associated with the mid-gut, fat body and malpighian tubules (Hodgson et al., 1983). In KQR and HDS strains of $H$. armigera, the content of cytochrome P450s and cytochrome $b_{5}$ increased from the $3^{\text {rd }}$ to $6^{\text {th }}$ instar larva, in which it was at the highest level and then decreased gradually with the lowest value recorded in the pupal stage. Similarly, the MROD (7-methoxyresorufin O-demethylation) activity of the cytochrome P450s increases from the $3^{\text {rd }}$ to the $6^{\text {th }}$ instar and is at its maximum in $6^{\text {th }}$ instar larvae and then decreases with lowest activity occurring in pupae and moths (Qiu et al., 1999).

There is already evidence that the level of expression and degree of regulation of P450 enzymes is very variable even though individual insect P450s have not been 
studied for very long (Scott et al., 1998). CYP4D1 is expressed in all stages of development in Drosophila (Gandhi et al., 1992), while others, such as CYP6Z1 is only expressed in the adults of Anopheles gambiae (Nikou et al., 2003) and CYP6B2 only in the larvae of Helicoverpa armigera (Ranasinghe et al., 1997). Most of the insect P450s that have been studied are expressed in both sexes, although at least one, CYP6L1, is only expressed in male Blattella germanica (Wen \& Scott, 2001) and CYP312A1 in male Drosophila melanogaster (Kasai \& Tomita, 2003). Some P450s are found in only a few tissues, such as CYP6L1 in the reproductive tissues of Blattella germanica (Wen \& Scott, 2001), CYP4C7 and CYP15A1 in the corpora allata of Diploptera punctata (Sutherland et al., 1998; Helvig et al., 2004), CYP4G15 in the central nervous system of Drosophila melanogaster (Maîbèche-Coisine et al., 2000), while others are ubiquitous (CYP6D1 in house flies) (Korytko \& Scott, 1998). This study revealed that CYP6B6 is expressed in all developmental stages and the levels of expression were higher in larvae than in other developmental stages. The levels of expression of $C Y P 6 B 6$ in eggs, pre-pupae and pupae were very low, possibly because they derive little or no sustenance from the external environment. Adults were only fed $10 \%$ honey solution, in which there is little or no toxic secondary metabolites, which might account for the low level of CYP $6 B 6$ recorded in adults.

The above results indicate that the artificial diet fed to the larvae not only affected their rate of development but also the level of expression of the CYP $6 B 6$ gene. In addition there was a similar trend in the expression of CYP6B6 protein in the different larval stages with the lowest level recorded in $3^{\text {rd }}$ instar and highest in $6^{\text {th }}$ instar larvae. Therefore, in order to more effectively control cotton bollworm in the field it is important to determine when during its development CYP6B6 is expressed using the results of laboratory studies and predictions of its rate of development in the field.

ACKNOWLEDGEMENTS. This work was supported by the Science Foundation of Xinjiang Uygur Autonomous Region in China (2012211A018), Foundation of Student Research Training of Xinjiang University (XJU-SRT-Z11014) and the Natural Science Foundation of China (30960220).

\section{REFERENCES}

Ahmad M., Gladwell R.T. \& McCaffery A.R. 1989: Decreased nerve sensitivity is a mechanism of resistance in a pyrethroid resistant strain of Heliothis armigera from Thailand. - Pestic. Biochem. Physiol. 35: 165-171.

Brattsten L.B., Holyoke J.C.W., Leeper J.R. \& Raffa K.F. 1986: Insecticide resistance: Challenge to pest management and basic research. - Science 231: 1255-1260.

Chen S., Yang Y. \& Wu Y. 2005: Correlation between fenvalerate resistance and cytochrome P450-mediated O-demethylation activity in Helicoverpa armigera (Lepidoptera: Noctuidae). - J. Econ. Entomol. 98: 943-946.

FEYREISEN R. 2005: Insect cytochrome P450. In: Gilbert L.I., Iatrou K. \& Gill S.S. (eds): Comprehensive Molecular Insect Science - Biochemistry and Molecular Biology. Vol. 4. Elsevier, Oxford, pp. 1-77.
Forrester N.W., CAhill M., Bird L.J. \& Layland J.K. 1993: Management of pyrethroid and endosulfan resistance in Helicoverpa armigera (Lepidoptera: Noctuidae) in Australia. Bull. Entomol. Res. 1: 1-132.

Gandhi R., VaraK E. \& Goldberg M.L. 1992: Molecular analysis of a cytochrome P450 gene of family 4 on the Drosophila X chchromosome. - DNA Cell Biol. 11: 397-404.

Gunning R.V., Easton C.S., Balfe M.E. \& Ferris I.G. 1991: Pyrethroid resistance mechanisms in Australian Helicoverpa armigera. - Pestic. Sci. 33: 473-490.

Harrison T.L., Zangerl A.R., Schuler M.A. \& Berenbaum M.R. 2001: Developmental variation in cytochrome P450 expression in Papilio polyxenes in response to xanthotoxin, a host-plant allelochemicals. - Arch. Insect Biochem. Physiol. 48: 179-189.

Helvig C., Koener G., Unnithan G.C. \& Feyreisen R. 2004: CYP15A1, the cytochrome P450 that catalyzes epoxidation of methyl farnesoate to juvenile hormone III in cockroach corpora allata. - Proc. Natl Acad. Sci. USA. 101: 4024-4029.

Hodgson E. 1983: The significance of cytochrome P450 in insects. - Insect Biochem. 13: 237-246.

Hodgson E., Rose R.L., Ryu D.Y., Falls G., Blake B.L. \& Levi P.E. 1995: Pesticide-metabolizing enzymes. - Toxicol. Lett. 3: $73-81$.

HunTer M.D. \& McNeIL J.N. 1997: Host-plant quality influences diapause and voltinism in a polyphagous insect herbivore. - Ecology 78: 977-986.

Kasai S. \& Tomita T. 2003: Male specific expression of a cytochrome P450 (Cyp312a1) in Drosophila melanogaster. Biochem. Biophys. Res. Commun. 300: 894-900.

Korytko P.J. \& SCOtT J.G. 1998: CYP6D1 protects thoracic ganglia of houseflies from the neurotoxic insecticide cypermethrin. - Arch. Insect Biochem. Physiol. 37: 57-63.

Li X., Berenbaum M.R. \& Schuler M.A. 2002: Plant allelochemicals differentially regulate Helicoverpa zea cytochrome P450 genes. - Insect Mol. Biol. 11: 343-351.

Liu Z.D., Li D.M., Gong P.Y. \& Wu K.J. 2004: Life table studies of the cotton bollworm, Helicoverpa armigera (Hübner) (Lepidoptera: Noctuidae), on different host plants. Environ. Entomol. 33: 1570-1576.

Liu X.N., Liang P., Gao X.W. \& Shi X. 2006: Induction of the cytochrome P450 activity by allelochemicals in the cotton bollworm, Helicoverpa armigera (Hübner). - Pestic. Biochem. Physiol. 84: 127-134.

JiANG M.X. \& Zhang X.X. 1998: Effects of photoperiods on developmental time and pupal weight of the cotton bollworm, Helicoverpa armigera. — Entomol. Knowl. 35: 71-73.

McCaffery A.R., Head D., Tan J., Dubbledam A.A., SubranMARIAM V.R. \& AGHAN A. 1997: Nerve insensitivity resistance to pyrethroid in heliothine Lepidoptera. - Pestic. Sci. 44: 237-247.

Maîbèche-Coisine M., Monti-Dedieu L., Aragon S. \& DauphinVillemant C. 2000: A new cytochrome P450 from Drosophila melanogaster, CYP4G15, expressed in the nervous system. - Biochem. Biophys. Res. Commun. 273: 1132-1137.

Nikou D., Ranson H. \& Hemingway J. 2003: An adult-specific CYP6 P450 gene is overexpressed in a pyrethroid-resistant strain of the malaria vector, Anopheles gambiae. - Gene 318: 91-102.

QIU X.H. \& Leng X.F. 2000: The tissue distribution of monooxygenase activities of cotton bollworm, Helicoverpa armigera. - Acta Ecol. Sin. 20: 299-303.

QIU L.H., Zhang W.J. \& Li X.W. 1999: Changes of component contents and enzyme activities of microdomal mixed- 
function oxidases in Helicoverpa armigera (Hubner) during different stages. - Chin. J. Pestic. Sci. 1: 45-50 [in Chinese, English abstr].

QIU X.H., Li W. \& Leng X.F. 2001: Comparison of components and activities of microsomal P450 monooxygenases from the cotton bollworm, Helicoverpa armigera during different developmental stages. - Acta Entomol. Sin. 44: 142-147.

Qiu X.H., Li W., Tian Y. \& Leng X.F. 2003: Cytochrome P450 monooxygenases in the cotton bollworm (Lepidoptera: Noctuidae): tissue difference and induction. - J. Econ. Entomol. 4: $1283-1289$.

RANASINGHE C. \& HoBBS A.A. 1998: Isolation and characterization of two cytochrome P450 cDNA clones for CYP6B6 and CYP6B7 from Helicoverpa armigera (Hübner): possible involvement of CYP6B7 in pyrethroid resistance. - Insect Biochem. Mol. Biol. 28: 571-580.

Ranasinghe C., Headlam M. \& Hobbs A.A. 1997: Induction of the mRNA for CYP6B2, a pyrethroid inducible cytochrome $\mathrm{P} 450$, in Helicoverpa armigera (Hubner) by dietary monoterpenes. - Arch. Insect Biochem. Physiol. 34: 99-109.

ScotT J.G., LiU N \& WeN Z.M. 1998: Insect cytochromes P450: diversity, insecticide resistance and tolerance to plant toxins. - Comp. Biochem. Physiol. (C) 121: 147-155.

Sutherland T.D., Unnithan G.C., Andersen J.F., Evans P.H., Murataliev M.B., Szabo L.Z., Mash E.A., Bowers W.S. \& FEYREISEN R. 1998: A cytochrome P450 terpenoid hydroxylase linked to the suppression of insect juvenile hormone synthesis. - Proc. Natl Acad. Sci. USA 95: 12884-12889.
TAN W. \& GUO Y. 1996: Effects of host plant on susceptibility to deltamethrin and detoxification enzyme of Heliothis armigera (Lepidoptera: Noctuidea). - J. Econ. Entomol. 89: $11-14$.

TAYLOR R.L. 1931: On "Dyar's rule" and its application to sawfly larvae. - Ann. Entomol. Soc. Am. 24: 451-466.

Wen Z. \& ScotT J.G. 2001: Cytochrome P450 CYP6L1 is specifically expressed in the reproductive tissues of adult male German cockroaches, Blattella germanica (L.). - Insect Biochem. Mol. Biol. 31: 179-187.

Wu Y.C.1977: A survey on the peanut noctuids in Kwangtung province. - Acta Entomol. Sin. 4: 445-450 [in Chinese, English abstr].

Wu K. \& Gong P. 1997: A new and practical artificial diet for the cotton bollworm. - Insect Sci. 4: 277-282.

Wu K.J. \& Li M.H. 1993: Nutritional ecology of the cotton bollworm, Helicoverpa armigera (Hübner): life tables of the population on the artificial diets whit different protein levels. - Acta Entoml. Sin. 36: 21-28 [in Chinese, English abstr].

Willoughby L., Chung H., Lumb C., Robin C., Batterham P. \& DARBON P.J. 2006: A comparison of Drosophila melanogaster detoxification gene induction responses for six insecticides, caffeine and phenobarbital. — Insect Biochem. Mol. Biol. 36: 934-942.

Yang Y., Wu Y., Chena S., Devineb G.J., Denholm I., Jewess P. \& Moores G.D. 2004: The involvement of microsomal oxidases in pyrethroid resistance in Helicoverpa armigera from Asia. — Insect Biochem. Mol. Biol. 34: 763-773.

Received April 11, 2012; revised and accepted June 22, 2012 